\title{
Subjects of ectogenesis: are 'gestatelings' fetuses, newborns or neither?
}

\author{
Nick Colgrove
}

Department of Philosophy, Baylor University, Waco, Texas, USA

\section{Correspondence to}

Dr Nick Colgrove, Philosophy,

Baylor University, Waco, TX

76706, USA;

nick_colgrove@baylor.edu

Received 3 April 2019

Revised 29 May 2019

Accepted 6 July 2019

Published Online First

24 July 2019

\section{CSLinked}

- http://dx.doi.org/10.1136/ medethics-2019-105723

Check for updates

(c) Author(s) (or their employer(s)) 2019. No commercial re-use. See rights and permissions. Published by BMJ.

To cite: Colgrove $\mathrm{N}$.

$J$ Med Ethics

2019;45:723-726.

\section{ABSTRACT}

Subjects of ectogenesis - human beings that are developing in artificial wombs (AWs) - share the same moral status as newborns. To demonstrate this, I defend two claims. First, subjects of partial ectogenesis - those that develop in utero for a time before being transferred to AWs - are newborns (in the full sense of the word). Second, subjects of complete ectogenesis - those who develop in AWs entirely — share the same moral status as newborns. To defend the first claim, I rely on Elizabeth Chloe Romanis's distinctions between fetuses, newborns and subjects of ectogenesis. For Romanis, the subject of partial ectogenesis 'is neither a fetus nor a baby' but is, instead, a 'new product of human reproduction'. In this essay, I begin by, expanding upon Romanis's argument that subjects of partial ectogenesis are not fetuses while arguing that those subjects are newborns. Next, I show that the distinction that Romanis draws between subjects of partial ectogenesis and newborns needs to be revised. The former is a kind of the latter. This leads us to an argument that shows why different moral statuses cannot be justifiably assigned to subjects of partial ectogenesis and subjects of complete ectogenesis, respectively. As subjects of partial ectogenesis share the same moral status as newborns, it follows that subjects of complete ectogenesis share the same moral status as newborns as well. Iconclude by considering implications that this essay may have for the research and development of AW technology and conceptual links between a subject's moral status and birth.

\section{INTRODUCTION}

In this essay, I argue that subjects of ectogenesis ('gestatelings') share the same moral status as newborns. In the first two sections, I defend the claim that subjects of partial ectogenesis are newborns. The first section makes use of Elizabeth Chloe Romanis's distinction between fetuses and gestatelings, as well as accepted definitions of terms like 'live birth'. ${ }^{\text {i1 }}$ Next, I argue that subjects of partial ectogenesis are a kind of newborn. Thus, even though Romanis's suggestion-that gestatelings are not newborns-is false, there is still a way to refine the gestateling/newborn distinction in productive ways. Both the sections, therefore, refine Romanis's distinctions in a way that leads to the conclusion that subjects of partial ectogenesis are newborns. Moving forward, I use this finding to demonstrate that subjects of complete ectogenesis also share the same moral status as newborns. Thus, all the three sections combine to support the

${ }^{\mathrm{i}}$ Accepted by international legal and medical authorities, that is. main claim of this essay: subjects of ectogenesiswhether partial or complete-share the same moral status as newborns

I conclude by considering the potential implications of this essay. First, whatever restrictions and safeguards are in place concerning medical research on newborns should be applied to gestatelings. This is significant given the alternatives. Gestatelings may be said to deserve the same protections as embryos or fetuses, for example. Those protections are (often) relatively weak compared with protections afforded to newborns. That gestatelings deserve the same protections afforded to newborns, therefore, is not a trivial matter. Additionally, as I show that subjects of complete ectogenesis share the same moral status as newborns (despite having not been born), it follows that birth is not necessary to be deserving of the moral status and protections afforded to newborns. This seems to put pressure on the view that birth is a necessary rite of passage to be deserving of relatively significant moral status and legal protections.

\section{SUBJECTS OF PARTIAL ECTOGENESIS ARE NEWBORNS}

To show that subjects of partial ectogenesis are newborns, I rely on (1) Romanis's distinction between fetuses and subjects of partial ectogenesis and (2) a consideration of how terms like 'live birth' are defined by international legal and medical authorities. First, Romanis distinguishes between three types of human subjects: fetuses, newborns and gestatelings. These distinctions may not be morally relevant, Romanis notes, but they are important distinctions to make if we are to avoid confusion when discussing artificial womb (AW) technology. ${ }^{1}$ The subject of an AW, after all, 'is neither a fetus nor a baby' but is, instead, a 'new product of human reproduction' altogether. ${ }^{1}$ The term 'fetus' clearly does not refer to gestatelings because 'most medical definitions of the fetus imply it is located inside a human gestator by describing it as 'unborn'. ${ }^{1}$ Gestatelings are not located within a human gestator. So 'fetus' does not refer to them. Researchers who have called gestatelings 'fetuses', therefore, have misapplied the term. ${ }^{2}$ Misapplication of terms introduces confusion into discussions of AWs. To avoid that confusion, we need to keep fetuses and gestatelings separate.

As we unpack Romanis's distinction between fetuses and gestatelings, I will restrict 'gestateling' to subjects of partial ectogenesis (as this is what Romanis does for much of her essay). 'Fetus' does not apply to gestatelings because fetuses are 'unborn'. Gestatelings are not 'unborn'. Does that 
imply that gestatelings have been born? For a moment, suppose it does. In that case, why distinguish between gestatelings and newborns (as Romanis does)? Perhaps gestatelings are a type of newborn. If so, then there is merit to using the term 'gestateling', just as there is merit to using terms like 'preterm' and 'term' to refer to different types of newborns. If we take that approach, however, Romanis's claim that the subject of an AW 'is neither a fetus nor a baby' is false. ${ }^{1}$ It is correct that gestatelings are not fetuses, but incorrect to say they are not babies (ie, newborns).

In contrast, perhaps gestatelings are neither 'unborn' nor 'born'. ii Given how terms like 'live birth' are usually understood, however, this suggestion is implausible. The WHO, European Union, US Law and international medical community all define 'live birth' (or 'birth') in ways that apply to gestatelings. ${ }^{3-7}$ iii For example, the WHO defines 'live birth' as

\begin{abstract}
...the complete expulsion or extraction from its mother of a product of conception, irrespective of the duration of the pregnancy, which, after such separation, breathes or shows any other evidence of life-for example, beating of the heart, pulsation of the umbilical cord or definite movement of voluntary muscles-whether or not the umbilical cord has been cut or the placenta is attached. ${ }^{3}$
\end{abstract}

Gestatelings satisfy this definition. ${ }^{\text {iv }}$ If we agree with Romanis that 'fetus' should not be used to refer to gestatelings-as doing so introduces confusion into discussions of AWs-then claiming that gestatelings have not been born also introduces confusion. We should refer to gestatelings as newborns because terms like 'live birth' straightforwardly apply to them (ie, they have been born). Refusing to acknowledge that subjects of partial ectogenesis have been born would either demonstrate a misunderstanding of terms like 'live birth' or would rely on a highly unconventional use of those terms.

In response, maybe we should redefine what it means to be born. ${ }^{\mathrm{v}}$ Maybe so, but that discussion moves us beyond the scope of this essay. For now, I will simply suggest that given widespread agreement on the terms, we need a compelling reason to think that current conceptual boundaries require revision. Further, given the legal ramifications that would follow from redefining what it means to be born, such a task should not be taken lightly. Either way, what is clear is that terms like 'live birth'-as currently used by international legal and medical authoritiesapply to subjects of partial ectogenesis.

Despite having been born, however, Romanis claims that 'newborn' 'cannot appropriately' be used to refer to gestatelings. ${ }^{1}$ She explicitly states that the subject of an AW 'is neither a fetus nor a baby'. ${ }^{1}$ It is a different sort of thing. For Romanis, therefore, it is not just that 'newborn' does not apply to gestatelings. Gestatelings are (for Romanis) a distinct 'product of human reproduction'. 1

In tracing this line of thought, it makes sense to say that 'newborn' does not refer to gestatelings if gestatelings are not newborns. In that case, to call a gestateling 'newborn' would be to call it something it is not (just like calling a gestateling 'fetus' is to call it something it is not). But if gestatelings are newborns, then it is unclear why they 'cannot appropriately be described' as such. ${ }^{1}$ Thus, if one wishes to argue that 'newborn' does not

\footnotetext{
${ }^{i i}$ An anonymous reviewer presses this point.

${ }^{i i i}$ Among these references is the same source that Romanis uses when discussing the definition of 'fetus.'

iv Again, I am restricting 'gestatelings' to subjects of partial ectogenesis for now.
}

${ }^{\mathrm{v}}$ An anonymous reviewer raises this concern. refer to gestatelings, the most intuitive option is to suggest (as Romanis does) that gestatelings are not newborns.

\section{REVISING THE GESTATELING/NEWBORN DISTINCTION}

Why think that gestatelings are not newborns? ${ }^{\mathrm{vi}}$ Romanis gives four reasons: (1) gestatelings are treated (or behave) 'as if' they have not been born, (2) newborns exercise some independent capacity for life but gestatelings do not, (3) gestatelings depend on AWs in ways that newborns do not depend on neonatal intensive care technology, and (4) gestatelings are socially 'isolated' in ways that newborns are not. ${ }^{1}$

None of these features is relevant to whether or not something is a newborn, however. Being a newborn means having been born recently. Subjects of partial ectogenesis have been born recently. Thus, they are newborns. The issue has nothing to do with how they are treated, how they behave, the capacities they exercise, their relative dependence on technology or their social interactions. None of the features Romanis discusses, therefore, support the claim that gestatelings are not newborns.

Romanis may simply be concerned that terms like 'newborn baby' carry connotations of features associated with term infants. Usually, gestatelings are not term infants. Connotations associated with 'newborn' are, therefore, misleading when applied to gestatelings. By analogy, however, it would be strange to assert that 'fruit' cannot appropriately be used to refer to tomatoes given that connotations of 'fruit' include sweetness (whereas tomatoes are relatively savoury). 'Fruit' is appropriately used in reference to tomatoes because they are fruit. This is so regardless of the connotations associated with 'fruit'. Likewise, 'newborn' is appropriately applied to subjects of partial ectogenesis because they are newborns. This is so regardless of connotations associated with 'newborn'.

Still, we can salvage Romanis's distinction. 'Newborn' is an ambiguous term. It may refer to preterm infants, term infants or subjects of partial ectogenesis, for example. 'Gestateling', therefore, provides us with a clearer way of referring to a particular kind of newborn. Thus, the new term is more informative than 'newborn'. This may be enough to justify Romanis's development of new terminology for subjects of ectogenesis.

There are, however, three reasons why this adjustment does not support Romanis's original distinction. First, it undermines her claim that it is 'inappropriate' to call gestatelings 'newborns'. Referring to a gestateling as a newborn may violate some Gricean maxim(s) in certain contexts-in that, the speaker fails to be as informative as they could be, given that there are more informative terms available than 'newborn'. ${ }^{8}$ But that does not support the claim that 'newborn' cannot appropriately be used to refer to gestatelings. Second, the revised distinction undermines Romanis's suggestion that subjects of ectogenesis are a 'new product of human reproduction'. ${ }^{1}$ Gestatelings are not a new type of product; they are newborns (although very young ones). Third, the revised distinction does not allow Romanis to bracket the question of 'whether there is any difference in moral status' between subjects of partial ectogenesis and newborns. ${ }^{1}$ That is, Romanis claims her distinction leaves open the possibility that gestatelings and newborns have different moral statuses. The adjusted distinction-which specifies that gestatelings are a kind of newborn-closes off the possibility

${ }^{\text {vi } ~ ' G e s t a t e l i n g ' ~ i s ~ s t i l l ~ r e s t r i c t e d ~ t o ~ s u b j e c t s ~ o f ~ p a r t i a l ~ e c t o g e n e s i s . ~}$

Colgrove N. J Med Ethics 2019;45:723-726. doi:10.1136/medethics-2019-105495 
of neutrality. Subjects of partial ectogenesis deserve the same moral treatment and protection as newborns because they are newborns.

\section{SUBJECTS OF COMPLETE ECTOGENESIS ARE (MORALLY EQUIVALENT TO) NEWBORNS}

I have argued that subjects of partial ectogenesis are newborns. So, they share the same moral status as newborns. From this, it can be demonstrated that subjects of complete ectogenesis share the same moral status as newborns (and deserve whatever protections come with it). This is so despite the fact that subjects of complete ectogenesis have not been born. I proceed in two parts. First, by explaining why subjects of complete ectogenesis are not newborns. Second, by arguing that they deserve the same moral status as newborns nonetheless.

\section{Subjects of complete ectogenesis are not newborns...}

Subjects of complete ectogenesis have not been born (in a technical sense). They have never been extracted or expelled from the body of a human gestator. Subjects of complete ectogenesis are not rightly described as 'unborn' either as they are not 'still being gestated in utero. ${ }^{17}$ So, subjects of complete ectogenesis are neither born nor unborn. This may sound contradictory. But there are two senses of 'unborn' to consider here. First, a human subject is 'unborn' when it is presently developing in utero. Second, a human subject may be said to be 'unborn' when it has never been completely extracted from the body of a human gestator.

Fetuses are unborn in both senses. They are presently developing in utero and have never been completely extracted from the body of a human gestator. Subjects of partial ectogenesis are unborn in neither sense. They are not presently developing in utero, nor is it the case that they have never been completely extracted from the body of a human gestator. Subjects of complete ectogenesis are not unborn in the first sense as they are not presently developing in utero. But they are unborn in the second sense as they have never been completely extracted from the body of a human gestator.

As subjects of complete ectogenesis are unborn (in some sense), it might be tempting to think that they are more like fetuses than newborns. If so, then perhaps subjects of complete ectogenesis are morally equivalent to fetuses, not newborns. As fetuses often receive fewer protections than newborns, it would follow that subjects of complete ectogenesis (may) receive fewer protections than newborns as well. But despite being unborn (in a sense), subjects of complete ectogenesis share the same moral status as newborns (given that they share the same moral status as subjects of partial ectogenesis, as we will see).

\section{...But they share the same moral status as newborns}

In defence of the claim that subjects of complete ectogenesis share the same moral status as newborns, consider a case:

Separated Twins: an embryo is formed in vitro. That embryo splits into identical twins: Corey and Paula. Paula is successfully implanted into the uterus of her biological mother. Corey is placed in an AW. At week 16, the twins' mother decides to have Paula transferred to an AW.

Given the arguments in the first two sections, it follows that Paula has been born. Whatever moral status applies to newborns (generally) should apply to Paula. But Corey has not been born. So, it does not seem to follow (automatically) that the same moral status should apply to Corey. What should we conclude about Corey's moral status?

In response, consider what Beauchamp and Childress call 'the formal principle of justice': Equals must be treated equally, and unequals must be treated unequally. ${ }^{9}$ The formal principle of justice seems to be a 'minimal requirement' that is 'common to all theories of justice'. 9 Granted, it does not tell us when two individuals are equal in the relevant sense. But regarding Paula and Corey, many variables-features that distinguish individuals-have been controlled. Both subjects come from the same parents, they are the same age, both exist within AWs, both have the same genetic makeup and so on. If we want to treat Corey differently than Paula, the formal principle of justice requires that we explain why the two are unequal in some relevant way.

The main way in which Paula and Corey differ is that Paula existed in utero for part of her life, but Corey never did. Is this enough to justify assigning them different moral statuses? Failure to defend the claim that the difference is sufficient-while insisting that we should be allowed to treat Paula and Corey differently-will run contrary to the demands of justice. There is a good reason to think that the past events of Paula and Corey's lives (respectively) are not sufficient to justify treating them differently. We typically do not justify drawing a distinction in the moral status of two innocent, comparable individuals that have different backgrounds. Children who were delivered via caesarean section, for example, do not have greater (or lesser) moral status than those delivered vaginally. Adults who were raised in abusive homes do not have greater (or lesser) moral status than (otherwise comparable) adults who were raised in non-abusive homes.

Perhaps this is because appropriate principles of justice usually do not draw distinctions based on 'differences for which the affected individual is not responsible'. ${ }^{9}$ Neither Paula nor Corey are responsible for their respective pasts. To draw a moral distinction between them given that their pasts were-through no fault of their own-different in some way(s) would run contrary to the requirements of justice. Thus, Corey-a subject of complete ectogenesis-deserves the same moral status and treatment as Paula (a newborn).

An objector may worry that this argument undermines the moral permissibility of abortion (or, alternatively, provides a justification for infanticide). In either case, the argument would prove far too much. To illustrate the objection, consider another case:

Separated Twins 2.0: an embryo is formed in vitro. That embryo splits into identical twins: Carl and Paul. Paul is successfully implanted into the uterus of his biological mother. Carl is transferred to an AW. At week 16, the twins' mother decides to abort Paul.

If the discussion following Separated Twins is correct, then Carl deserves the same moral status as a newborn. But Paul seems comparable with Carl. So, Paul seemingly shares the same moral status as Carl. If we are convinced that it is wrong to kill Carl (because infanticide is wrong), then it is wrong to kill Paul. That is, aborting Paul is morally impermissible as well. Alternatively, if we are convinced that abortion is permissible (and so, believe it is permissible to kill Paul), then it follows that killing Carl (ie, infanticide) is permissible as well. Both outcomes run contrary to the (fairly common) view that abortion is permissible whereas infanticide is not. Thus, either way, the Separated Twins case proves too much. 
In response, there is ample room to argue that Paul is not relevantly like Carl. Paul's life is presently being sustained by the body of another person. Carl's life is not. Thomson famously argued that having a right to life does not give a fetus the right to use another person's body for survival. ${ }^{10}$ If that is correct, then Paul's mother may abort him without violating his right to life, even if it would be impermissible for her to kill Carl. Thus, the original Separated Twins case does not undermine the view that abortion is permissible whereas infanticide is not. Although the (im)permissibility of abortion goes far beyond the scope of this paper, the point to emphasise is this: my claim-that subjects of complete ectogenesis should receive the same moral status as newborns-does not automatically imply that abortion is impermissible. Nor does it imply that infanticide is permissible. So, worries that the argument 'proves too much' are unfounded.

Returning to the original Separated Twins case, the case can be generalised. ${ }^{\text {vii }}$ That is, it may be applied to subjects of complete ectogenesis in general. Corey is not relevantly different than other subjects of complete ectogenesis (once we control for age, development and so on). There is a good reason to assign to Corey the same moral status as a newborn. Requirements of justice would, therefore, imply that other gestatelings comparable to Corey-whether subjects of complete ectogenesis or partial ectogenesis-deserve the same moral treatment. We can run a Separated Twins case for a wide range of subjects (no matter their age, stage of development and so forth). In each case, it turns out that we lack sufficient justification for treating subjects of complete ectogenesis differently than (comparable) subjects of partial ectogenesis (ie, newborns).

\section{IMPLICATIONS}

I have argued that subjects of ectogenesis-whether partial or complete-deserve the same moral status and protections as newborns. I will conclude by outlining three potential implications of this thesis. First, and most importantly, as AW technology develops, whatever protections apply to newborns (in an experimental or clinical setting) should be extended to gestatelings. This is significant given the alternatives. Gestatelings might, for example, be afforded the same protections as embryos, fetuses or newborns. Of these groups, newborns tend to receive the highest moral status and highest levels of legal protection. That gestatelings are afforded those same protections (as opposed to being treated as embryos or fetuses) is, therefore, no small matter.

Second, my thesis does not imply that gestatelings have a right to life nor does it imply they have a right not to be killed. Arguments from Tooley, Singer, and Giubilini and Minerva, and Räsänen support the permissibility of infanticide. ${ }^{11-16}$ Räsänen, for example, argues that parents' right to 'genetic privacy' gives them a right to end the lives of newborns that carry their genetic code. ${ }^{14-16}$ The same arguments may apply to gestatelings. Kaczor, Manninen, Hendricks, and Rodger et al, on the other hand, argue that infanticide is impermissible. ${ }^{17-21}$ If infanticide is impermissible, then insofar as gestatelings share the same moral status as newborns, terminating gestatelings will be just as wrong as infanticide. So while I show that gestatelings share the same

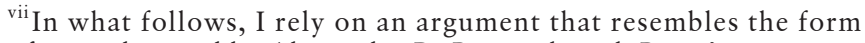
of one advanced by Alexander R. Pruss, though Pruss's argument occurs in a different context. ${ }^{22}$ moral status as newborns, it is still open whether or not it is permissible to kill gestatelings (insofar as the (im)permissibility of infanticide is an open matter). What cannot be justified is assigning to gestatelings a different moral status than the status assigned to newborns.

Third, having shown that subjects of complete ectogenesis share the same moral status as newborns, it follows that a human individual need not be born to be deserving of whatever moral status is assigned to born individuals. As discussed above, this does not imply that all unborn human beings deserve the same moral status as newborns. But it does undermine the view that birth is a necessary rite of passage to be deserving of relatively significant moral status and legal protection.

Acknowledgements The author thanks Kelly Kate Evans, Derek McAllister, Joona Räsänen, John Rosenbaum, Allison Krile Thornton, Michael Willenborg, Pete Younger, and two anonymous reviewers at Journal of Medical Ethics for their comments.

Contributors NC is the sole contributor.

Funding The authors have not declared a specific grant for this research from any funding agency in the public, commercial or not-for-profit sectors.

Competing interests None declared.

Provenance and peer review Not commissioned; externally peer reviewed.

\section{ORCID iD}

Nick Colgrove http://orcid.org/0000-0003-0506-353X

\section{REFERENCES}

1 Romanis EC. Artificial womb technology and the frontiers of human reproduction: conceptual differences and potential implications. J Med Ethics 2018:44:751-5.

2 Partridge EA, Davey MG, Hornick MA, Homick M, et al. An extra-uterine system to physiologically support the extreme premature lamb. Nat Commun 2017;8:1-15.

3 Maternal mortality ratio. In World Health Organization: health statistics and information systems. 2019 https://www.who.int/healthinfo/statistics/ indmaternalmortality/en/ (Accessed 21 Mar 2019).

4 Natality. In United Nations statistics division. 2017 https://www.who.int/healthinfo/ statistics/indmaternalmortality/en/ (Accessed 21 Mar 2019).

5 Born-alive infants protection act. In An act to protect infants who are born alive, 107th Congress of the United States. 2002 https://www.govinfo.gov/content/pkg/ PLAW-107publ207/html/PLAW-107publ207.htm (Aaccessed 19 Mar 2019).

6 Funai EF, Norwitz ER. Management of normal labor and delivery. UpToDate 2019 https://www.uptodate.com/contents/management-of-normal-labor-and-delivery (Accessed 27 May 2019).

7 Martin E. Concise medical dictionary. Oxford: Oxford University Press, 2015.

8 Grice P. Studies in the way of words. Cambridge, MA: Harvard University Press, 1989

9 Beauchamp TL, Childress JF. Principles of biomedical ethics. $6^{\text {th }}$ Edition. New York: Oxford University Press, 2009.

10 Thomson JJ. A defense of abortion. Philos Pub Aff 1971;1:47-66.

11 Tooley M. Abortion and infanticide. Philos Pub Aff 1972;2:37-65.

12 Singer P. Practical ethics. $2^{\text {nd }}$ Ed. Cambridge: Cambridge University Press, 1999.

13 Giubilini A, Minerva F. After-birth abortion: why should the baby live? J Med Ethics 2013;39:261-3.

14 Räsänen J. Pro-life arguments against infanticide and why they are not convincing. Bioethics 2016;30:656-62.

15 Ectogenesis RJ. abortion, and a right to the death of the fetus. Bioethics 2017;31:350-2.

16 Räsänen J. Why pro-life arguments still are not convincing: A reply to my critics. Bioethics 2018:32:628-33.

17 Kaczor C. The Ethics of Abortion: Women's Rights, Human Life, and the Question of Justice. $2^{\text {nd }}$ Edition. New York: NY: Routledge, 2015.

18 Kaczor C. A dubious defense of 'after-birth abortion': A reply to Räsänen. Bioethics 2018;32:132-7.

19 Manninen BA. Yes, the baby should live: a pro-choice response to Giubilini and Minerva. J Med Ethics 2013;39:330-5.

20 Hendricks P. There is no right to the death of the fetus. Bioethics 2018;32:395-7.

21 Rodger D, Blackshaw BP, Wilcox C. Why arguments against infanticide remain convincing: A reply to Räsänen. Bioethics 2018;32:215-9.

22 Pruss AR. I was once a fetus: that is why abortion is wrong: In. Napier $S$, ed. Persons, moral worth, and embryos: a critical analysis of pro-choice arguments from philosophy, law, and science. New York: Springer, 2011:19-42. 